Article

\title{
Extending the Life Cycle of EEE-Findings from a Repair Study in Germany: Repair Challenges and Recommendations for Action
}

\author{
Sina Rudolf ${ }^{1, *}$, Steffen Blömeke ${ }^{1}$, Jan Felix Niemeyer ${ }^{1}$, Sebastian Lawrenz ${ }^{2} \mathbb{D}$, Priyanka Sharma ${ }^{2}$, \\ Sven Hemminghaus ${ }^{3}$, Mark Mennenga ${ }^{1}$, Kerstin Schmidt ${ }^{3}$, Andreas Rausch ${ }^{2} \mathbb{D}$, Thomas S. Spengler ${ }^{3} \mathbb{D}$ \\ and Christoph Herrmann ${ }^{1}$
}

\section{check for}

updates

Citation: Rudolf, S.; Blömeke, S.;

Niemeyer, J.F.; Lawrenz, S.; Sharma,

P.; Hemminghaus, S.; Mennenga, M.; Schmidt, K.; Rausch, A.; Spengler, T.S.; et al. Extending the Life Cycle of EEE-Findings from a Repair Study in Germany: Repair Challenges and Recommendations for Action. Sustainability 2022, 14, 2993. https:// doi.org/10.3390/su14052993

Academic Editor: Ting Chi

Received: 31 January 2022

Accepted: 1 March 2022

Published: 4 March 2022

Publisher's Note: MDPI stays neutral with regard to jurisdictional claims in published maps and institutional affiliations.

Copyright: (c) 2022 by the authors. Licensee MDPI, Basel, Switzerland. This article is an open access article distributed under the terms and conditions of the Creative Commons Attribution (CC BY) license (https:/ / creativecommons.org/licenses/by/ $4.0 /)$.
1 Institute of Machine Tools and Production Technology, Technische Universität Braunschweig, 38106 Braunschweig, Germany; s.bloemeke@tu-braunschweig.de (S.B.); jan-felix.niemeyer@tu-braunschweig.de (J.F.N.); m.mennenga@tu-braunschweig.de (M.M.); c.herrmann@tu-braunschweig.de (C.H.)

2 Institute for Software and Systems Engineering, Clausthal University of Technology, 38678 Clausthal-Zellerfeld, Germany; sebastian.lawrenz@tu-clausthal.de (S.L.); priyanka.sharma@tu-clausthal.de (P.S.); andreas.rausch@tu-clausthal.de (A.R.)

3 Institute of Automotive Management and Industrial Production, Technische Universität Braunschweig, 38106 Braunschweig, Germany; sven.hemminghaus@tu-braunschweig.de (S.H.); kerstin.schmidt@tu-braunschweig.de (K.S.); t.spengler@tu-braunschweig.de (T.S.S.)

* Correspondence: s.rudolf@tu-braunschweig.de

\begin{abstract}
The increasing amount of waste from electrical and electronic equipment and the resulting environmental issues are challenging, since product life cycles are too short, and companies continue to rely on linear (business) models. The Circular Economy is an approach to meet these challenges by extending the product lifetime. One way to extend the product lifetime is to repair them. However, since there has been no detailed research on the repair sector yet, this article aims at conducting a repair study in Germany to understand the repair process and get insights into typical failure patterns. Therefore, we analyze the repair sector's current barriers from different perspectives, especially of customers and businesses. We discuss the results of the repair study, where 382 repair attempts were conducted, with a total success rate of 55\%. Moreover, the participants were interviewed to understand their barriers and motivation for repair. Based on the study's interim findings, recommendations for action are given to make the repair services more attractive for the repairer and customer. Based on the findings, an interdisciplinary approach to improve repair processes by using a digital repair portal is derived.
\end{abstract}

Keywords: repair; repair study; life cycle extension; circular economy; electrical and electronic equipment (EEE); waste electrical and electronic equipment (WEEE)

\section{Introduction}

Electrical and electronic equipment (EEE) has become an essential part of everyday life and is indispensable in modern societies. Higher levels of incomes, shorter life cycles, growing urbanization and further global industrialization are leading to increasing amounts of EEE [1]. EEE are often complex due to multiple materials, different joining techniques and product structure, which is usually optimized for manufacturing and assembly. Some of the materials used are valuable (e.g., gold, silver), while some materials are potentially hazardous (e.g., mercury) or are classified as conflict materials (e.g., cobalt) [1,2]. At the same time, the average lifetime of EEE is decreasing to under five years currently, which results in steadily increasing amounts of electronic waste [3]. However, the lifetimes vary greatly depending on the category of equipment (e.g., mobile phones or large household appliances). As a consequence, the global amount of waste of electrical and electronic 
equipment (WEEE) was 53.6 million tons in 2019 and is expected to be 74.7 million tons in 2030 [1]. This means that global WEEE is expected to grow by around 2 million tons annually [1]. Even most European countries with a formal WEEE-management system, such as Germany, have relatively low collection and recycling rates of around 40 to 50\% [4]. Through illegal exports, WEEE often ends up in developing countries and has particularly harmful effects on the environment and human health if not handled in an environmentally sound manner [1,2].

The Reuse and Recycling of WEEE can contribute to sustainability and climate goals. A key enabler for using resources in a sustainable way is the successful implementation of a Circular Economy. The overall aim of the Circular Economy for EEE is to create environmental quality besides economic prosperity and social equity by implementing activities to reduce, reuse and recycle in production, distribution and consumption processes to close resource cycles [5]. These activities are also called cascade use, in which repair is followed by reuse and recycling as the last of the end-of-life activities. The activities are based on the EU waste hierarchy, with decreasing utility of the product and increasing (ecological) impacts of the processes along their hierarchy position [6,7]. According to the waste hierarchy, waste should be avoided in the first place before it has to be treated. Repair as the highest cascade in the hierarchy is beneficial from an environmental and economic perspective as it prolongs the product use time of EEE and, thus, slows down the production and consumption cycle and saves energy due to a low disassembly degree in comparison to, e.g., refurbishment and recycling [8-10]. In contrast to remanufacturing and refurbishment, repair only replaces defective components and achieves a lower target quality. Thus, it might not meet the functionality of a new product and might be more inferior regarding reliability specifications [11].

Even though repair can offer economic and environmental benefits, it has not been fully studied in research so far. Most studies in the literature focus on defects, while the repair processes of EEE are mainly based on surveys and interviews. A survey-based study by [10] concluded that the low price of new products and the poor access to competent repairers are the main barriers for customers to repair EEE. Based on interviews, [12] investigated the drivers and barriers of the repair of EEE and the different roles of involved stakeholders. The results show that a growing user's awareness is a driver for an increase in repair but that repair activities are currently not properly promoted and supported by communities [12]. Nazli explored the repair motivation and barriers for smartphones and non-electronics and identified factors that affect users' repair behavior in general [13]. The users' repair behavior is influenced by technical (e.g., required knowledge, skill and time), emotional (e.g., attachment to the product) as well as value (e.g., condition of the product) factors [13]. Cobbing et al. analyzed the reparability of smartphones, tablets and laptops through a repair index based on ratings from the 'Do-it-yourself' (DIY) repair platform iFixit and the availability of spare parts and repair manuals by OEM [14]. Only three of the 17 analyzed OEMs provide easy access to spare parts and repair manuals to encourage the repair of their products [14]. Raihanian Mashhadi et al. analyzed break and repair narratives of EEE reported by customers from a survey by iFixit [15]. The results show that product damage is often caused by the user and can also be successfully repaired in most cases by unprofessional repairers [15]. Based on a survey of professional repairers of customer electronics in the U.S., [16] found that uncertainty in determining labor costs is a challenge for repairers and that customers have less willingness to repair their low-priced EEE. Different defects of washing machines and dishwashers were analyzed by [17]. Some weak but relevant components of the household appliances were, in most cases, the reason for the failure [17]. In the U.S. and EU, policymakers are attempting to increase the number of repairs through the legal frameworks of the EU Ecodesign and U.S. Right to Repair legislation. Svensson-Hoglund et al. identified a wide range of legal barriers to the repair of EEE [18]. The product design as well as intellectual property, consumer laws, taxation and the supply and demand of the repair services currently hinder the repair attempts [18]. 
However, data from different accomplished repair attempts and frequent failure patterns of EEE are missing in recent literature. In addition, the data collection of the repair process and defects is applicable only to specific products and is difficult to compare. Important parameters of the repair process, such as the repair time and the rate of successful attempts, are also missing in the current studies.

\section{Research Objective and Outline of the Paper}

While repair is important from economic and environmental perspectives, recently, it has nevertheless not been accepted: Study results show that the demand for repairs remains very low, with just $9.56 \%$ of customers having ever repaired broken household EEE [19]. This leads to the question of why repair activities currently seem not attractive enough. Therefore, the goal is to understand the current barriers of repair activities. This aim goes along with the implication of identifying the main stakeholders in the repair area and understanding their attitudes towards repair services.

In order to support this understanding, two approaches have been followed in this research: First, a literature-based reflection on the barriers of repairing EEE has been conducted from the perspective of the main stakeholders. Second, an own repair study has been conducted to further elaborate and reflect on already-identified barriers. The repair study focuses on the barriers related to EEE and their repair service and was therefore carried out to answer the following research questions:

(i) What are current challenges for the not-company-bounded (free) repair services of EEE on an industrial scale in Germany? (Sections 2 and 4)

(ii) What are typical failure patterns of different EEE products? (Section 4)

(iii) How can the identified barriers be overcome? (Section 5)

The discussion of these questions helps in the derivation of recommendations for action in regard to the involved stakeholders in the repair process.

\section{Background}

The average amount of global EEE consumption is growing by 2.5 million tons annually [1]. At the same time, the average lifetime is decreasing, and many devices are being replaced, even though they still work well or can be repaired [3]. This leads to a huge amount of WEEE. Improper handling of WEEE has a negative impact on the environment and human health. For example, 98 million metric tons of $\mathrm{CO}_{2}$-equivalents are released from discarded refrigerators and air conditioners that are not disposed of in an environmentally sound manner alone. This is approximately $0.3 \%$ of global energyrelated emissions [1]. As a result, valuable materials and functioning products as well as components are lost. Without the intent by its owner, EEE becomes WEEE once it has been discarded and generates one of the fastest growing waste streams [20].

Strategies for extended product use and the avoidance of WEEE are provided by the concept of the Circular Economy, with approaches aiming at reducing resource consumption and minimizing emissions [1,5]. The central principle of Circular Economy, besides aiming at sustainable development, is to use materials and resources in several cycles for as long as possible and to avoid inefficient use of resources by discarding them $[5,7,21]$. The successful implementation of the Circular Economy is based on new business models and responsible customers [5]. Although the positive environmental impact of a lifetime extension has already been proven, the environmental aspect has been considered only subordinately in the literature. Furthermore, from an economic perspective, repair is beneficial as it increases the demand for skilled labor. According to a survey, $77 \%$ of the European citizens would rather repair their products than buy new ones [22]. The main reasons against repair of used EEE are the lack of attractive repair services and the attitude of customers towards used equipment and repair $[15,23]$. Since the defect of a product is with $55.6 \%$ the main cause of a product's replacement [24], and a repair can increase the useful life by restoring product functionality [10], it is necessary to understand and solve the current barriers in the field of repair. The barriers are not limited to the technical 
feasibility of the repair, but they concern many other aspects, such as customers as well as economic and political boundary conditions.

\subsection{Stakeholder Involved in Repair Activities}

To understand the repair sector, it is necessary to identify the key stakeholders and their influence on repair services. The repair of an EEE is realized if a need by the owner of an EEE exists and an attractive offer of a repair service is available. Consequently, the repairer and the customer have a major influence on the decision so that they both act as the main decision-maker and main performer of the repair [25]. That is why they are attributed to the foreground stakeholder system in Figure 1. To conduct the repair, the repairers are mostly dependent on the complex access to the spare part supply that is mainly provided by the OEM and further spare part suppliers [18]. Subsequently, the background system is also of high interest, with stakeholders like the OEM, government, spare part supplier, logistics, NGOs and the recycler to foster circular repair activities. Subsuming this, the repair sector consists of many influential stakeholders and has not yet been adequately investigated [26].

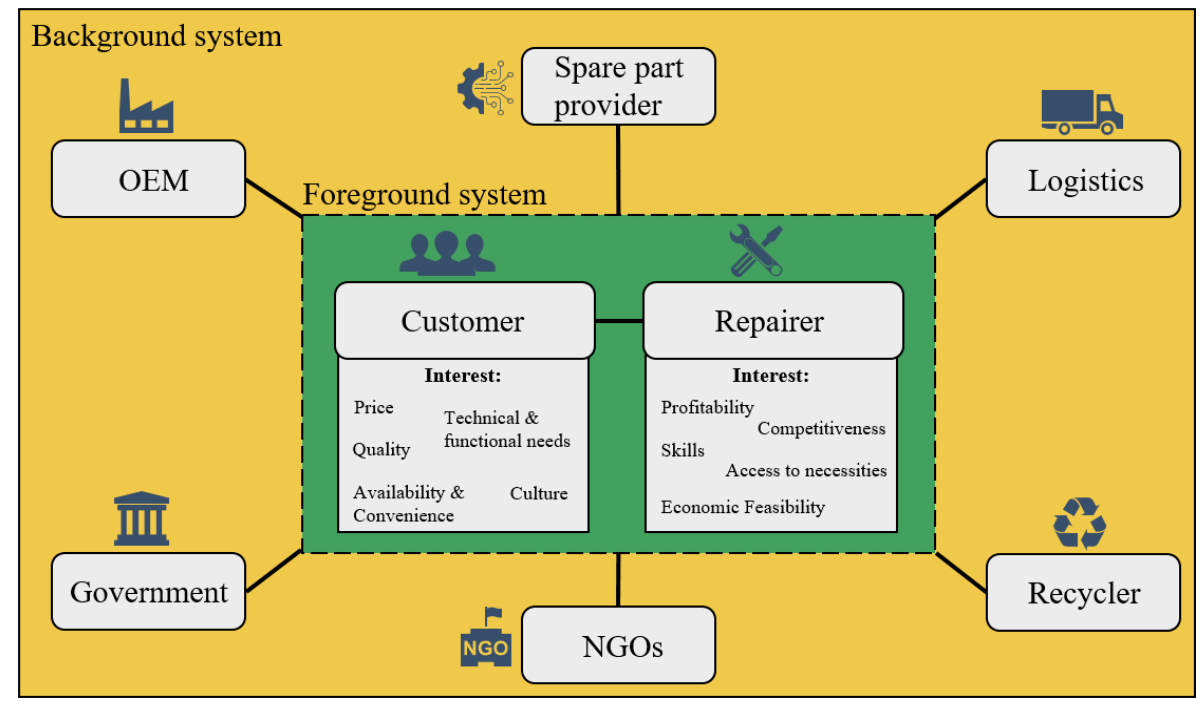

Figure 1. Relevant stakeholders for the repair of EEE, based on [18].

Repair activities can be distinguished by different service types: Repair services include those offered by professionals like manufacturers and contract repairers (OEMauthorized repairers), by independent repairers, and those provided by semi- or nonprofessionals within the DIY movement (private individuals or repair cafés) [18]. Most research has focused on professional or semi-professional offers, whereas only few insights into DIY-repair services exist [10]. DIY activities are mainly based on repair instructions, published as open access video tutorials or textual and photographical manuals on platforms, e.g., iFixit. OEM-based repair activities or independent repairers can further be differentiated into web-based offers and on-site assistance, whereby both options come with their own advantages and disadvantages (e.g., customer proximity, specializations on product categories or brands, economies of scale). Hence, a customer faces a multitude of repair options and the complex dependencies between the actors of the background system. Beyond that, the decision for a repair depends not only on the different repair offers and their dis-/advantages, but also on the potential competition with the purchase of a new or used device [27-29].

\subsection{Barriers for Repair}

While, in many cases, the repair of EEE is possible, in practice, different barriers prevent and complicate the repair option so that the repair activities seem less attractive. The various barriers can be classified into different categories, such as customer-, product- 
and legal barriers, as presented in the following to answer the first research question. These categories are derived from the foreground system of stakeholders involved and structure the various barriers and challenges. Customer-related barriers include the obstacles of the owner of the product to decide whether to repair or not. The repairers' perspective and their technical challenges of the repair process are reflected by the product-related barriers. Legal barriers affect both actors in the foreground system and describe the legal constraints that hinder repair.

\subsubsection{Customer-Related Barriers}

If a product is defective or no longer fully functional, the customer can decide whether or not to attempt a repair. The price of repairing a defective EEE has the most significant influence on the decision of a customer for repair or replacement [30]. Customers might be willing to repair their product if the associated repair costs of labor and spare parts do not exceed a certain undesirable threshold [17]. For example, the willingness to pay for the repair of small EEE is estimated to be about $20 \%$ of the replacement costs [31]. A difference can be made between the technical and functional lifetime: products at the end of their functional lifetime (i.e., defective devices) might not be repaired if they are additionally at the end of their technical lifetime (e.g., CD- or MiniDisc-player) [32]. In particular, devices that are subject to heavy use or EEE that can be easily replaced by the customer are exchanged more frequently than other devices on average, even if repair was financially attractive [18,33]. Hence, in terms of costs, customers sometimes do not decide rationally, as they decide for a more expensive replacement instead of an economically more viable repair [29].

Besides the pricing, (missing) information or knowledge can also be a customerrelated barrier for repair. For example, customers rarely estimate the expected lifetime extension through repair due to missing information on the actual product condition and the potentials of repair. This competes with the assumption that new products are of a higher quality and often sold with warranty [34]. Consequently, the value and durability of repaired and refurbished products is not assessed equally by customers, even if lifespan and quality are the same as for new devices [34]. The lack of information also leads to lower confidence of OEM or professional repair services. This goes along with short innovation life cycles of new products and the desire for a new EEE [35]. In addition, due to internetaccessible information, the EEE user knows much about the EEE's performance in its past and about possible failed repair attempts [36]. This could lead to minimizing confidence in the longevity of the EEE and, subsequently, may be a reason against another repair attempt, as the perceived quality of the service or product does not seem to be given [10].

A further customer-related barrier relates to the unavailability of the EEE from the time of the defect until the successful repair. Depending on the damage and the availability of spare parts, the time required for repair may increase. During this time, the customer may have to find a substitute or have to do without it for a while. Especially devices that make life hard to do without daily use, such as mobile phones, are therefore more likely to be replaced by the customer than repaired [33,37]. Therefore, the more the customers need the product in everyday life, the less likely they are to choose repair over replacement.

\subsubsection{Product-Related Barriers}

Many barriers to repair result from decisions in product design [18]. The product design has a significant impact on product life and can make repair difficult or impossible. On the one hand, the use of low-quality materials and components shortens the product life and durability of EEE [38], and on the other hand, some products cannot be dissembled and repaired without being destroyed $[39,40]$. Examples for these problems are the use of glue and non-destructive connections, which can make repair more difficult. In case of batteries, OEMs often make use of adhesives and solder to assemble batteries in EEE [41]. As a result, specialized tools and knowledge are required for disassembly. Furthermore, decisions about the product's reparability and the use of specialized tools for repair are 
made in the design phase and are a barrier during the repair attempt [38]. Often, the repair is hindered by a lack of information, e.g., circuit diagrams and component specifications, and spare part supply, which make repairs unattractive due to missing predictions of, e.g., required cost and time. The lack of availability or sourcing of spare parts poses a major repair challenge.

Another indirect obstacle and reason for unsuccessful repair processes are spare parts and required special tools, especially for laptops, TVs, game consoles, smartphones, etc. [42]. Spare parts are often not available or too expensive [43-45]. The sourcing of spare parts can be either too time-consuming due to global supply chains or too costly, e.g., for original equipment. Further bureaucratic barriers, such as individual customs restrictions and tax liability, also make it difficult to obtain spare parts. The same problem applies with the need for specific special tools which are required for the repair process $[43,45,46]$.

Other problems are missing software updates for various products, such as smart TVs. A device might still work in general; however, due to not existing updates, a couple of functions may not be working any longer.

All of these mentioned problems are solvable, since most of them exist due to economic reasons. A design for repair and recycling is often relatively easy to implement, but the right legal regulatory framework is still missing.

\subsubsection{Legal Barriers}

From a political and legal point of view, in recent years, the EU has created a comprehensive set of regulations on product responsibility in the electronics sector in the form of various directives to make the OEMs of EEE more accountable for their products [46-48].

Currently, policy makers have not established a comprehensive legal framework for the repair opportunity for customers and professional repairers. The European Green Deal, published in 2019, promises to prioritize waste prevention measures in its Circular Economy Action Plan (CEAP). These include making as many products as possible more easy to repair and reuse, and allowing customers to choose durable and repairable products [49]. The CEAP will also "analy[z]e the need for a 'right to repair'" [49] to empower the customer's choices. It is currently difficult to estimate how the needs of customers and repairers will be met by legislation in the future. However, the current attempts of politics and justice do not yet lead to a significant change in the industry and transformation to a Circular Economy [28].

Except for the latest EcoDesign-directive, less attention is currently being paid to the reparability and durability of EEE. The EU's EcoDesign-directive aims at reducing the environmental impact of EEEs by taking into account their entire life cycle. Since 2021, some product-specific regulations of the EcoDesign-directive have addressed elements such as reparability and the design of the products. OEMs are required to provide repair manuals for certain products and to design products that can be repaired with standard tools without damaging the product $[49,50]$. However, regulations have only come into force for a few products, such as refrigerators, washing machines, televisions and monitors [49,50]. Nevertheless, a more comprehensive legal framework to ensure the durability and reparability of the entire product spectrum of EEE is missing so far.

From the perspective of repairers, the lack of access to the necessary resources and product knowledge and the current legislation in favor of OEMs hinder the repair of many EEE [18]. For a professional repair, access to certain resources such as spare parts or specialized tools is a necessary requirement. However, on a legal basis, OEMs are currently not obliged to ensure the availability of necessary spare parts to replace defective parts [51]. In addition, specialized tools are often required to disassemble defective EEE, which are not available on the general market [18]. Without these resources, failure analysis and repair are, in most cases, impossible for repairers. OEMs seem more interested in selling new products and less in repairing products that have already been sold. Therefore, unauthorized repairers and private individuals are not provided with product knowledge for disassembly and repair, such as professional repair manuals or schematics from the 
OEM $[18,28]$. The product knowledge and resources needed can enable an efficient repair process, but OEMs are not legally obligated to provide them.

In summary, there are crucial social, technical, economic and legal barriers that currently hinder efficient and economic repair for both repairer and customer. As shown in Figure 2, there is an interdependence between the different barriers, and the transitions between the categories are seamless. For instance, solving legal barriers can reduce the cost of repair, making it more attractive to customers. The conscious customer's decision to repair EEE might change the industry and influence policy as well as legislation.

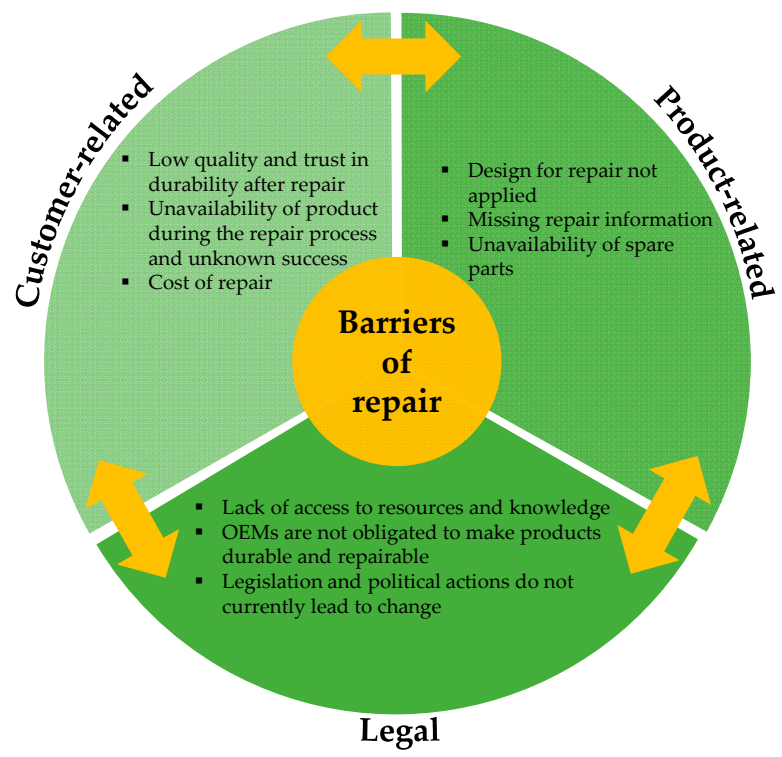

Figure 2. Barriers to repair from different perspectives.

\section{Methodology of the Repair Study and Data Collection}

In order to achieve a deeper understanding of the repair barriers in Germany and to gain insights into the complex repair business, especially from the perspective of brandindependent repairers, a repair study was conducted as part of the "EffizientNutzen" project. In this project, data-based business models for cascade use were developed, and the extended product use, and, thus, also the repair, of EEE was examined. The overall aim of the repair study was to identify the challenges in the repair context and to derive recommendations for action. In this study, a mixed-methods approach was chosen. On the one hand, the repair process and the technical challenges were investigated through a descriptive quantitative proceeding in cooperation with Robert Bosch GmbHGermany (see Section 3.1). On the other hand, results from conducted quantitative and qualitative customer surveys have been presented and used to understand the socio-technical dependency by identifying customer barriers and drivers (see Section 3.2).

\subsection{Repair Study Design}

The descriptive quantitative investigation took place at the project partner Robert Bosch GmbH, Automotive Aftermarket, Electronic Service (short: Bosch) in Lower Saxony, Germany, between January and December 2020, by repairing EEE. Bosch and its employees have the needed expertise, infrastructure and network to execute the repair study for a larger number of different EEE, because one of Bosch's business models is the repair of electronic devices in the automotive and household field.

In order to define the permissible EEE categories for the repair study, a systematic selection process took place. Here, it was identified that traditional repair companies focus mainly on the repair of large EEE, such as washing machines and electric stoves, as well as the repair of multimedia devices, such as smartphones, tablets and laptops. In contrast, repair services for products like $\mathrm{HiFi}$, electronic instruments and electronic toys are either 
not widespread or seem unattractive to users due to high repair and replacement costs. Furthermore, products like televisions and electrical instruments are, in general, higherpriced products, which are used for relatively long. Therefore, for a better understanding, for brand-independent business models besides the already existing ones, Bosch chose the product categories (1) HiFi and audio, (2) televisions and monitors, (3) electronic instruments, (4) electronic toys and (5) game consoles for investigation in the repair study. It was designed on the sequences of a generic repair process, taking into account logistics and spare part procurement in addition to the repair process itself.

In total, 382 repair attempts during the repair study were realized. The study was advertised as a free repair trial to interested people living in Germany. Relevant processes and parameters are illustrated in Figure 3. The free repair trial included free dispatch and free spare parts up to a value of 5 euros. Every participant was allowed to send in only one defective device which met the requirements mentioned above (e.g., accepted product categories) to ensure the participation of only non-commercial users. Another requirement for participation in the study was the contribution to a web-based survey, which asked for details on the defective product and personal repair experiences as well as wishes of the interested person, e.g., the preferred distance to the delivery point for the defective EEE. After registering for a repair date, the participant received a dispatch label, free of charge, and needed to send the safely packed product to the repairer. Alternatively, the owner could directly hand in the product at the repair location. If higher-priced spare parts were necessary, a repair could be carried out in consultation with the customer and cost sharing. If the repair trial was not successful, the customer could decide whether to have the defective product returned or have it professionally recycled (free of charge).

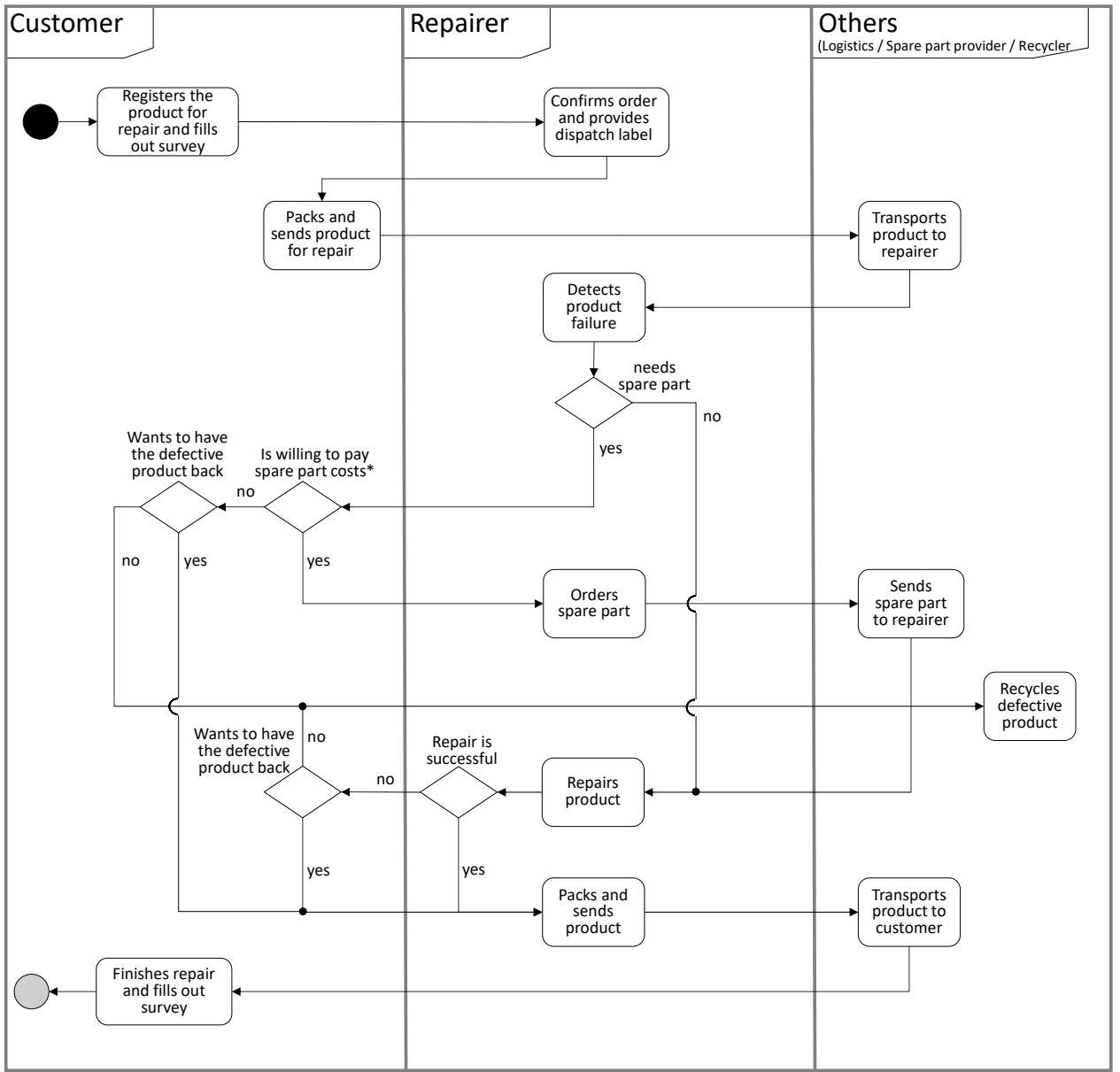

Figure 3. Process description of the repair study. ${ }^{*}$ Spare part costs up to $5 €$ per product were covered by the study. 


\subsection{Accompanying Surveys}

In order to understand the customer perspective and their drivers and barriers to use repair services, two types of surveys, both quantitative and qualitative, were conducted during the time of the repair study. The first survey, a quantitative, web-based survey, needed to be answered by every participant of the repair study during the registration process. The aim of the quantitative survey was to record the general participant data and thus gain a better understanding of the participant group by asking demographic questions, e.g., age, gender and questions about the defective EEE. As illustrated in Figure 4, the 382 participants in the repair study were primarily men, with $81 \%$, and they came from all over Germany. The participants belonged to all age groups, with an average age of 55 years and all levels of education and employment status. The participants were non-representative for the German repair sector, as the study was advertised as a free repair trial to interested people living across Germany (convenient sample).

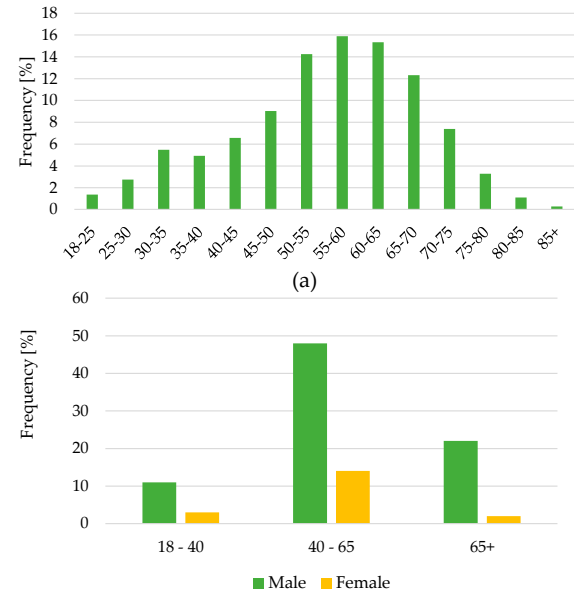

(b)

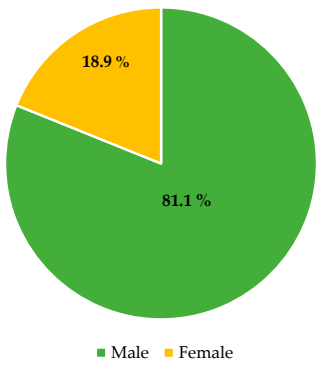

(c)

Figure 4. Overview of participants of the repair study $(n=382)$ with frequencies of the $(\mathbf{a})$ age distribution, (b) gender-age distribution and (c) gender distribution.

The questionnaire was based on existing literature, where themes like consumerrelated and economic barriers, requirements by consumers, drivers for repair, attitudes of consumers regarding repair and, for example, boundary conditions for DIY repair attempts were asked to consumers and professionals from repair shops [12,42,52]. The questionnaire was expanded by relevant questions resulting from the repair process at Bosch. The participants were asked about their defective EEE devices, their personal repair background (e.g., already-existing experiences) and requirements for the repair services. The repair requirements included options, e.g., of transport type, of treatment if repair was not successful, of urgency and theoretical willingness to pay for the repair outside the study. For the analysis of the anonymized data, a descriptive evaluation was chosen.

In the second survey, a qualitative customer survey in the form of semi-structured interviews was conducted at the end of the repair study. The goal was to understand more deeply the motivations, challenges and drivers for repair services. Therefore, all study participants were contacted via email and asked to contribute to the qualitative survey. From the responses given, participants were selected to represent various categories, including repair experiences, economic affairs, green image etc., ensuring the widest possible range of customer characteristics. A sub-group of 19 informants (3 females and 16 males) from the participants was asked about their general attitudes towards repair services and especially their satisfaction with the repair study. Interviews were conducted until no new findings emerged. The interview guide was developed based on existing literature on the field of repair services. The interviews were audio-recorded, lasted between 20 and $40 \mathrm{~min}$ and were examined with the video-conference tool Webex by 
two interviewers. A simplified transcription was chosen, and the anonymized data was analyzed with MAXQDA using a qualitative content analysis.

\section{Presentation and Discussion of the Results of the Repair Study}

The evaluation of the repair attempts revealed valuable insights into the repair sector of EEE. The results can be differentiated in technical results from the analysis of the repair process (see Section 3.1) as well as socio-economic results from the accompanying surveys (see Section 3.2). Both are presented in the following in more detail, which is followed by a discussion of the results and the limitations of the study to answer the first and second research question regarding barriers and typical failure patterns.

\subsection{Results from the Repair Process}

In total, 382 repair attempts during the repair study were realized.

The equipment sent for repair consisted largely of $\mathrm{HiFi} / \mathrm{Audio}$ and TV, with $69 \%$ and $18 \%$, respectively, whereas electrical instruments and toys were much lower in number. Approximately 55\% of the total received products were successfully repaired and returned to the customer. The average cost of spare parts was approximately $19.30 €$ per repair; however, the costs could not be determined for all procurements. The average repair time of an EEE at the repairer was about $5.5 \mathrm{~h}$. Especially TVs and monitors needed longer repair times. The repair success rate and the key error patterns differed significantly in the investigated product categories. Defects in the mechanics occurred most frequently across all products. Furthermore, it should be emphasized that circuit boards and batteries were often the cause of faults, although they were not present in all devices in significant sizes. Figure 5 shows the summarized results of the repair study, describing the processed products, the average required repair time per category, the repair success rate of each category and the key error patterns for those categories.

Key error patterns are important findings for optimization needs. Figure 5 illustrates the product-specific key error patterns, while Figure 6 visualizes the cross-product error patterns and their occurrence. With regards to defect patterns, the repair study shows that failures on the mechanics and motor, circuit board and connectors and contacts were identified as the most frequent causes of defects, whereby $15 \%$ of the products sent in had more than one error pattern. Capacitors, cables and switches were the main spare parts needed for the repair.

To classify the defect patterns, the product age of the products sent in was also recorded. Figure 7 shows the age of the EEE sent in between 1-50 years, with the average device being about 13 years old. The calculated median was almost 8 years. The majority of the EEE was outside the statutory warranty period of at least two years. Of the EEE which could not be successfully repaired, 39 devices (10.6\%) were handed over for professional recycling at the request of the customer. The study could not reveal a correlation between reparability and product age due to a too-heterogeneous product distribution.

\subsection{Findings from Accompanying Surveys}

In the interviews of the repair study, the most common barrier mentioned was the lack of (attractive) repair offers or at least the transparency about existing repair services (online, local and DIY). One major reason was the repair costs. Repair costs are often perceived as too high due to the prevailing opinion that repair services are expensive. Depending on the respective device type and the (new) acquisition costs, the price for repair services must not exceed a certain threshold (percentage rate of the price of a comparable new or refurbished device). 


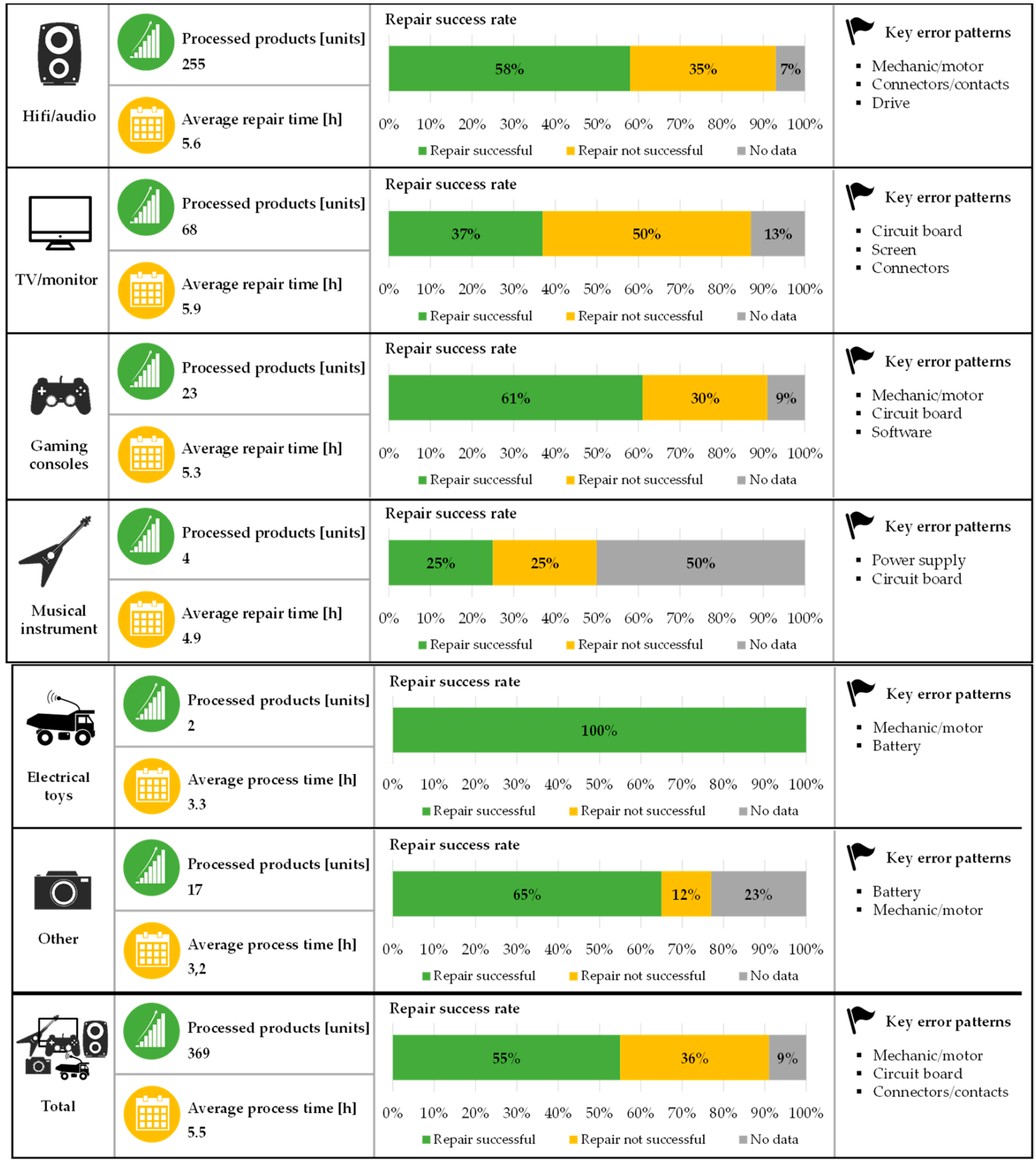

Figure 5. Summarized results of the processed products in the repair study.

Barriers, in particular those identified from a self-repair view (DIY), are the lack of availability of spare parts and, moreover, the lack of knowledge or availability of information, which prevent self-repair. Besides missing motivation or time, this led the DIY-repairers to participate in the repair study.

Minor barriers mentioned by the surveyed people were the repair time and, thus, the unavailability of their product during that time period. A further challenge was a significant price difference between repairing and buying a new product. Moreover, the customer's ability to evaluate the quality of repairs was limited, whereby the perceived quality may have seemed to be low. 


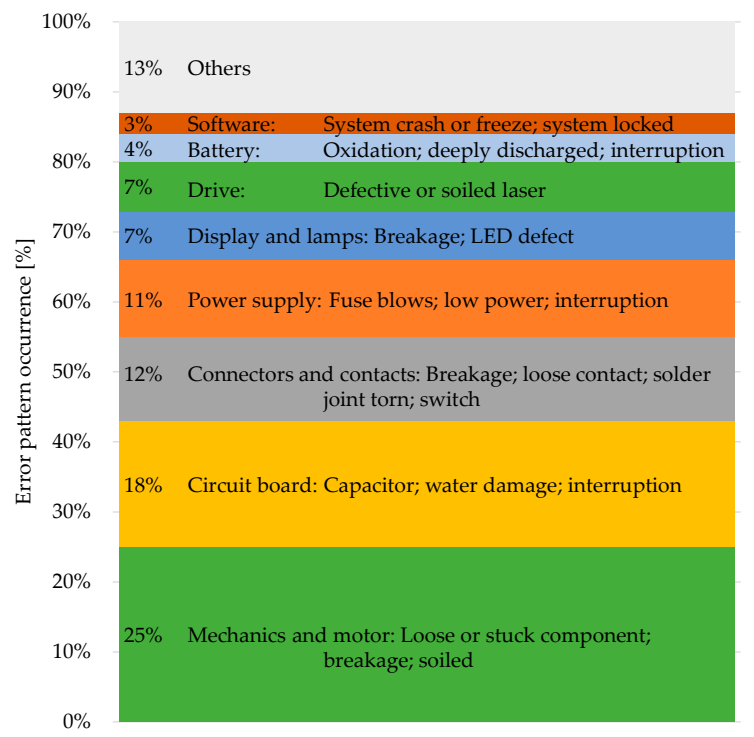

Figure 6. Cross-product error pattern occurrence and key reasons.

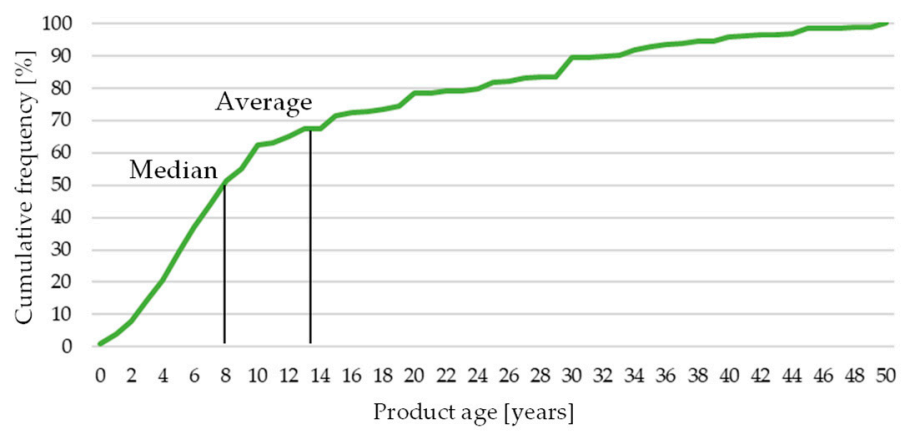

Figure 7. Cumulative frequency of product age.

As further reasons for participating in the study, participants mentioned, for example, the limited available storage space at home.

Additionally, participants were asked about their preference for how far away the drop-off location for defective EEE should be in order for them to still consider repairing it. The results were diverse within the possible options to select $(3 \mathrm{~km}, 10 \mathrm{~km}$ and $20 \mathrm{~km}): 20 \%$ of all participants selected $3 \mathrm{~km}$, whereas $40 \%$ selected 10 and $20 \mathrm{~km}$ each. Thus, we can infer that as $80 \%$ of the participants were ready to go up to 10 and $20 \mathrm{~km}$ to hand over their products, the radius of the drop off location being the nearest did not play a relevant role for repair.

\subsection{Discussion of the Results and Limitations of the Study}

With regard to the barriers of repair presented in Section 2.2, the main findings have been confirmed by the study's results and will be discussed subsequently.

The barrier regarding missing repair information mentioned by, e.g., [12] could be strongly confirmed. Missing information, such as manuals of schematics, led to long repair times in the study above the market average. This could be explained by the focus of the study, which was to successfully repair and understand as many typical failure patterns as possible, rather than conducting an economic repair. In many cases, the repair was carried out at the component level, which requires specific circuit diagrams, which are often not provided by official sources. Professional repairers can draw on their experience and, if available, on specially created repair instructions, while this lack of information prevents self-repair (DIY). 
The barrier of spare parts procurement could also be confirmed in the study. The lack of spare parts sources is one of the main reasons for unsuccessful repairs according to, e.g., $[44,45]$. In consultation with the industrial project partner, the reasons for missing spare parts are manifold. Often the repairer cannot find a source of supply for specific spare parts, also reported by [12]. In some cases, the price or delivery conditions, such as customs regulations and duties, are so high that the customer refuses a repair. Many of the parts, such as displays and printed circuit boards, cannot be ordered from authorized suppliers and had to be obtained from, e.g., eBay and other unauthorized sources. At OEMauthorized repairers, this may lead to difficulties in invoicing due to their legal policies. Furthermore, the global procurement may take very long. For the product category of $\mathrm{TV} /$ monitor, on the one hand, only approx. $40 \%$ of the required spare parts could be obtained. The reason might be the often complex and expensive replacement of circuit boards and screens, which can often also only be replaced as a whole. For game consoles, on the other hand, $90 \%$ of the required spare parts could be procured, which might be due to the lower component complexity and associated costs. Less complex components could be produced, e.g., by 3D-printing. However, this contradicts the intellectual property of the OEM [18].

Problems with the software were few but difficult to repair, especially for older EEE, where the reasons were often based on the manufacturer and its framework conditions. Even minor software-related defects, such as missing software updates or system crashes of smart-TVs, may usually only be handled by licensed repairers, which resulted in unrepaired products in the study. This is a problem, especially for independent and smaller repairers.

Another barrier concerns the transport. To interpret the low repair success rate of TVs and monitors in the study, it must be taken into account that transport damage often occurred, especially in the case of large and vulnerable flat-screen TVs. In consequence, they could not be repaired due to the high costs of screens and other linked spare parts. In particular, thin and fragile products are dependent on safe and, in the best case, original packaging. However, the proper available packaging is often lacking for old and bulky products, especially for the transport from the customer to the repairer.

The examination of a design for repair of different products was not in the focus of the study and was therefore considered subordinated, as the repairer cannot change the design for repair afterwards. Nevertheless, the repairer was faced by challenges resulting from a missing design for repair. This could be determined across many products, which reflects the findings in [18]. For example, special tools are required for many repair attempts due to the special product design [38]. Even the study's executive Bosch department, which is generally well equipped for the repair of EEE, had to purchase these to disassemble the devices and find the defects.

The main social challenge for repair shops, reported by repair experts at Bosch, was the need for qualified and experienced employees. The employees are faced with hardly any professional development opportunities within the repair business. This leads to a declining apprenticeship rate and, hence, a decreasing number of experts in the repair sector. Furthermore, the image of repairing and also the image and trust of different repairer types (e.g., licensed repairer, repair services from (big) manufacturers, free repairer, etc.) are challenging.

From a customer's perspective, and to some extent also from the perspective of the repairer, the barriers are primarily the perception of quality. Especially the lack of transparency or knowledge about the quality of repair services (and, thus, confidence in the longevity of the product after repair) as well as in the consideration of the priceperformance-ratio are customer reasons against repair. These barriers compete primarily with the option of buying new products, which were observed in [10,42]. Customers consider most repairs in comparison to a new purchase as too expensive. A distinction can be made between different types of customer demand with regards to different repair offers (e.g., customers who prefer online or local repair offers). Users' repair behavior is further influenced by their technical knowledge, skills, urgency, their attachment to the 
product, value and condition of the product reported by [13]. These vary between local, online and DIY offers.

The reparability of a product depends strongly on the errors that occur. The defects can be technologically not repairable or unprofitable. In the study, we could observe that an uncertain labor cost and time was a challenge for repairers to confirm [42]. Another finding of the study was that, based on the study's design, repair at the component level was more economical than the repair at the module level. This resulted from the fact that nonstandard modules are more expensive because they must be ordered from OEMs. Resulting higher personal costs for a longer process time were not considered. The additional effort for repairing on a component level can be high and may not be economically feasible outside of the study. Repair at the module level is usually faster and less complex due to the lower effort.

Beyond the study, we could observe that the repair decision of the customer is preferably considered the more expensive or durable the EEE is or the more emotionally attached the customer is to the EEE (see also [42]); however, sufficient data in the study itself are missing. Another reason for repairing might be the missing storage space at home. Large appliances tend to be repaired rather than purchased twice, as they would take up too much space. In contrast, defective smaller electronic toys and radios are stored at home. With the offer of free repair, the opportunity was often used by the participants to send in these products.

The evaluated data from the study as well as from the surveys were representative for the products investigated, but they were subject to the conditions of the scientific study (see Section 4). A limitation is, for example, that only previously defined device categories were repaired. Besides, the focus was on successful, not economic, repairs that could have resulted in long repair times (above market average) and thus high labor costs. The free repair attempt for the participants could have resulted in devices being sent in which were old or were little used and were therefore not representative for all EEE. These limitations should be taken into account, in particular, when developing possible business models based on the study's results.

Overall, the discussed barriers make repair less attractive and in general more expensive. Some of the discussed suggestions may not be welcomed by OEMs. It can be deduced that due to pressure from efforts such as the "right to repair" or other initiatives, OEMs are changing their business models, enabling self-repairs and only doing those themselves that are either due to safety-related framework conditions (e.g., dangers from working with electricity) or economic benefits. An example for supporting DIY self-repair is the cooperation between Motorola and the DIY-platform iFixit [53]. The authors point out that beyond the evaluated barriers, there may be further product-, process- or business model-specific barriers. Thus, in order to support the Circular Economy and make repair more attractive, holistic approaches need to be developed in the future.

\section{Recommendations for Action and Digital Approach}

Based on the findings of the repair study, recommendations for action can be derived towards overcoming the main barriers, as asked in the third research question. The findings show that political and technical measures, in particular, are needed to strengthen the repair sector in Germany. Therefore, in the following, recommendations for action are given to politicians and further stakeholders, such as OEM. In Section 5.2, a new, technologysupported overall concept for improving the repair process enabled by a repair portal is presented.

\subsection{Recommendations for Action}

The recommendations below aim at enabling manufacturers and contract repairers in particular as well as independent workshops to optimize their business model by reducing time-consuming and cost-intensive processes and to increase trust from the customer's perspective. The findings of the repair study combined with current, international bestpractice examples show that policy measures, in particular, need to be taken in order to 
strengthen the repair sector. Technological innovations can further expand the proposed political framework.

\subsubsection{Financial Incentive Systems}

Repair costs have a significant impact on customer decisions. The high overall cost of spare parts and labor costs of repair is a big social barrier. Reducing VAT on repair services might be one possible approach to increasing repair attractiveness. However, the implementation of tax reduction in Sweden has shown that it had a limited impact on the attractiveness of repairs $[18,54]$. A suitable and attractive solution could be the introduction of cash refund systems, like in the German state Thuringia. Customers who want their defective household EEE repaired will be reimbursed half of the repair costs, up to a maximum of $100 €$ per person and calendar year. To prevent abuse, the repair invoice and proof of payment must be submitted [55]. The offer was well accepted and led, in the short term, to a significant increase in repairs [56]. As the financial incentives have only recently been introduced, it is not yet possible to make any statements about the long-term effects, e.g., increased demand for repair services. Further instruments are repair funds, e.g., that established in France, where a part of the consumer's costs for the repair service is paid by producers, or repair vouchers, introduced, e.g., in Vienna, Austria, to partly pay the repair costs [57].

\subsubsection{Simplified Tools}

Special or even licensed tools are often required for repairs. Further, the ability to repair is made more difficult by the use of adhesive technologies (see Section 4.2). An appropriate solution would be the use of standardized tools. As soon as a tool is uncommon, the attractiveness of (DIY) repairs drops because (time) investments have to be made. This problem can also occur with (semi-) professional repairers and raises the investment costs. If the use of standard tools is not possible for technical reasons, the OEM should provide low-cost special tools to enable the repair of its products, especially in the DIY sector. It can also be conceivable to set up a business model in which spare parts, repair instructions and tools can be purchased directly from the manufacturer.

\subsubsection{Repair Instructions and Regulations}

Both DIY and commercial repair service providers benefit from a long-term provision of repair instructions and spare parts. For the DIY repair sector in particular, the combination of common household tools, repair instructions and simple procurement of spare parts would increase the attractiveness of the repair. OEMs should be legally obliged to provide repair instructions and to offer spare parts at fair prices. That could, in turn, be a factor in repair indexes and regulations. National and international repair regulations can help to make repair more attractive by obliging companies to simplify repairs. For example, France introduced a repair index for EEE in 2021 [58]. In addition to repair regulations, customers can estimate the cost of a possible repair more easily. Repair instructions and regulations can support the removal of barriers such as missing repair information.

Technological measures can be taken not only by political actors, but also by OEMs, independent repairers or other technology-oriented stakeholders, discussed in the following.

\subsubsection{Technological Support Systems}

In order to solve some barriers, such as lack of information and lack of availability or sources of spare parts, etc., innovative solutions in the form of technological support systems are needed. A promising, customer-oriented technological support system could be provided through the combination of a physical product and a digital twin (DT). A DT is a virtual replica of a physical product [59]. Within the production process of the physical product, the DT is linked to it. The aim of the DT is to trace the entire lifecycle of its physical counterpart and create more data availability and transparency about its condition. Targeted data on wear (e.g., average usage time, charging cycles, etc.) could be 
mapped and stored by the DT. Consequently, the DTs data can be used for, e.g., selling, repairing, etc. This is intended to increase customer confidence in the repaired or used product. However, the extensive collection of data creates new challenges regarding data privacy. The DT should therefore be compliant with data privacy guidelines. such as the General Data Protection Regulation (GDPR). Therefore, future work needs to focus on enabling DT as a technical support of repair and the Circular Economy with a balance of data privacy as well as data transparency.

\subsubsection{Extended Guarantee and Insurances}

To further counteract distrust, one possible solution could be offering a (extended) guarantee for the repair by the repair shops or associated insurances. In recent years, this has become increasingly widespread from manufacturers themselves, over dealers, i.e., MediaMarktSaturn (Media-Saturn-Holding $\mathrm{GmbH}$ ), Ingolstadt, Germany, to independent third parties, i.e., Wertgarantie SE, Hanover, Germany $[60,61]$. The services range from the repair of defined defects or general repair to a replacement device for the period of the defect (warranty of service) and are available in different durations. The insurer Wertgarantie SE, with offers in Germany, found out in a survey of its customers that the willingness to repair is much greater when insurance is available than for people without insurance. Equipment insurance could help to ensure that repairable equipment does not end up prematurely disposed of as easily as it does now. However, such insurance currently exists for only around 2\% of the electrical appliances in German households [62].

The recommendations for action mentioned here are a selection based on the findings of the repair study. Other promising approaches, such as 3D printing and the concept of EcoPoints in digital platforms, exist to increase the attractiveness of repairs $[16,63]$.

\subsection{The Repair Portal as a Digital Approach}

Following the results of the surveys, an overall approach to support the repair for EEE has been developed, which addresses the following requirements for a holistic and novel approach towards repair solutions:

- Financial attractiveness: Repair must be recognizably cheaper than the purchase of a new device.

- Simplified and time-saving process: Time is one of the highest cost factors in high-wage countries; accordingly, processes must be designed to be as simple and time-saving as possible.

- Transparent and comprehensible for customers: Processes and offers must be comparable and comprehensible for customers. Fluctuating and uncertain prices, for example, are obstacles for customers.

Based on these requirements, a new repair portal has been designed. The repair portal mainly focuses on the repairer side and is used for the repair of products. Here, information has been identified as central in supporting repair to be more time-effective. Repairers have always been using their knowledge and expertise in repairing products. In addition, platforms such as iFixit provide online repair guides and support DIY-people in repairing their products by themselves. Repairers have expertise and knowledge about repairing, whereas community-driven online platforms create an environment for DIY repairs. Professional repairers sometimes, in contrast, cannot share all of their internal knowledge and repair instructions on open platforms. Thus, along with open platforms, further knowledge bases are required for the repairers, too, in order for them to collect their internal knowledge and reuse it. Nevertheless, the growing number of varieties of electronics creates a new problem, i.e., a lack of repair information. Lack of information here means that stakeholders such as repairers do not have full information about the components, materials, its composition, new updates or how it can be repaired. In some cases, this information can be aggregated from various sources, but it could be a timely process. In order to solve this problem of lack of information, a repair database has been 
developed and implemented in the repair portal. So far, it contains data for a market survey, support for the creation of repair manuals and photos.

The required time to repair a product is one important factor in determining the overall repair price. A repairer needs time to find the fault and solution in order to repair a product. The repair portal aims at reducing the time to repair by assisting a repairer.

Figure 8 shows the overall process of the portal, which functions as follows: as the customer decides to send in the product for repair, all the information which is provided by the customer, such as product information and the fault, is added to the repair portal. When the product arrives at the repairer, the repairer requests for a repair manual or tutorial for the particular product and problem. The repair portal looks through the existing internal repair information for repair manuals. The internal repair information is a collection of the knowledge and expertise of the repairers gained through the executed repair process. If there is no internal information or repair guide available, the repair portal searches external sources such as repair information (e.g., manuals, tutorials) on the internet. The needed instructions include information on the mounting type and location as well as required tools. In addition, the best possible disassembly sequence and further product and component specifications are noted. A large part of the instructions consists of prepared graphics (analog to oriented ones, e.g., iFixit manuals) with instructions, so that the handling is further accelerated. Later, the repairer is asked to provide feedback if the external information was useful. The feedback is stored in the repair portal for future reference. In addition, the repairer is asked to add more information about the repair process (in case there is any), in order to generate internal information. Once the repair is conducted, the product is sent back to the customer.

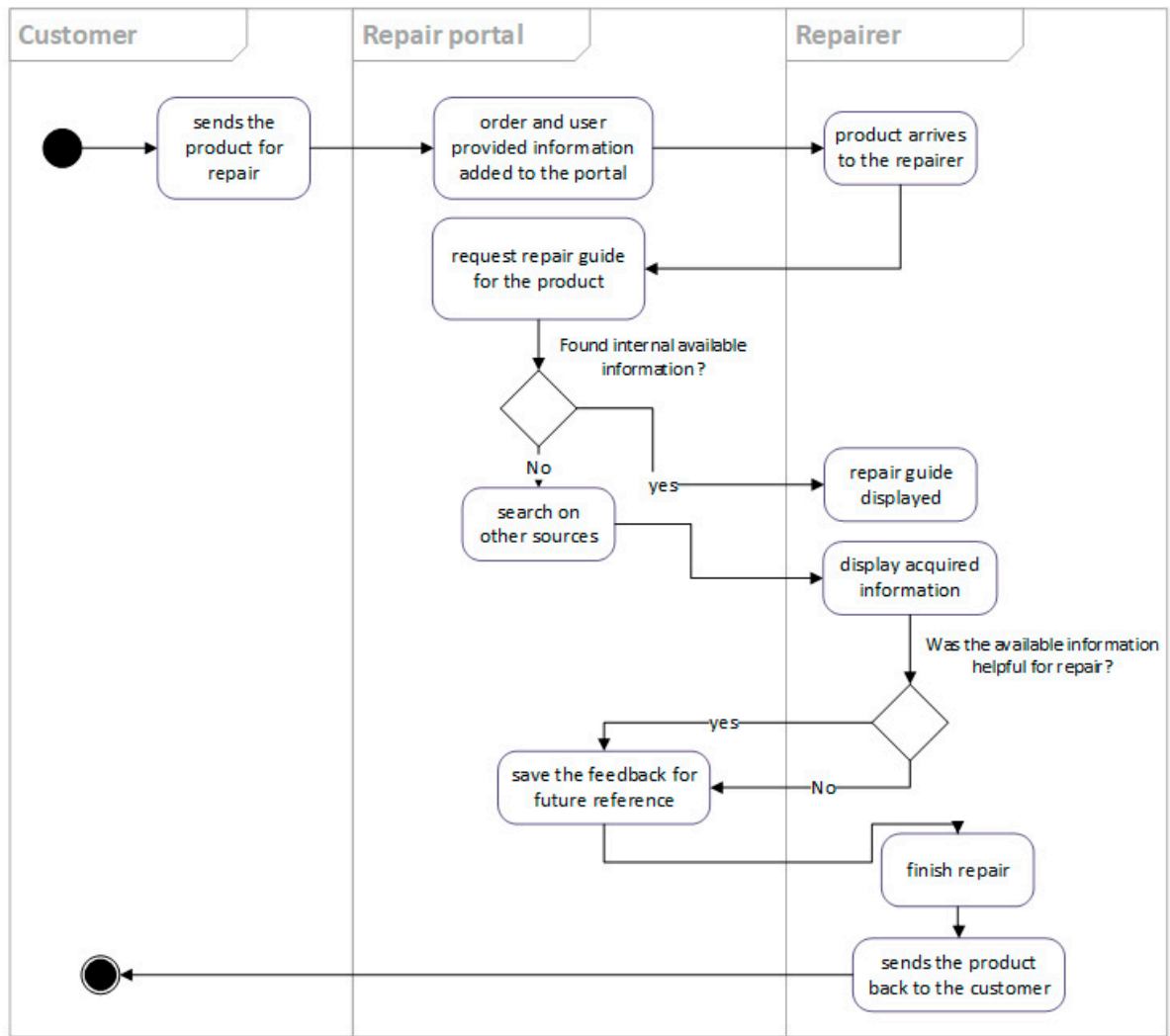

Figure 8. Overall process of the repair portal.

Thus, in the case of the repairer, rather than trying to find out how to repair a product, the information can be obtained from the repair portal. This, in return, decreases the overall repair time and also makes the repair cheaper for the customer. 
The creation of the repair manuals takes place in parallel and is not included in the above-mentioned process time. When an identical product is delivered, the repairer can access the instructions at his workstation and speed up the repair process by reading the implemented manuals as previously described.

The repair portal was developed with Flutter Web as a front end and uses ASP.NET for the back end. Furthermore, it has "Model View ViewModel" (Cubit) as an architectural pattern for the front end and "Model View Controller" for the back end. The repair portal was accessed by a tablet in the repair center. Figure 9 shows a screenshot of the homepage of the repair portal. Since it is always growing and learning repair related information, it should support reducing the repair time and cost by assisting the repairers in the future. The proposed repair portal was also tested in a prototypical implementation within our study.

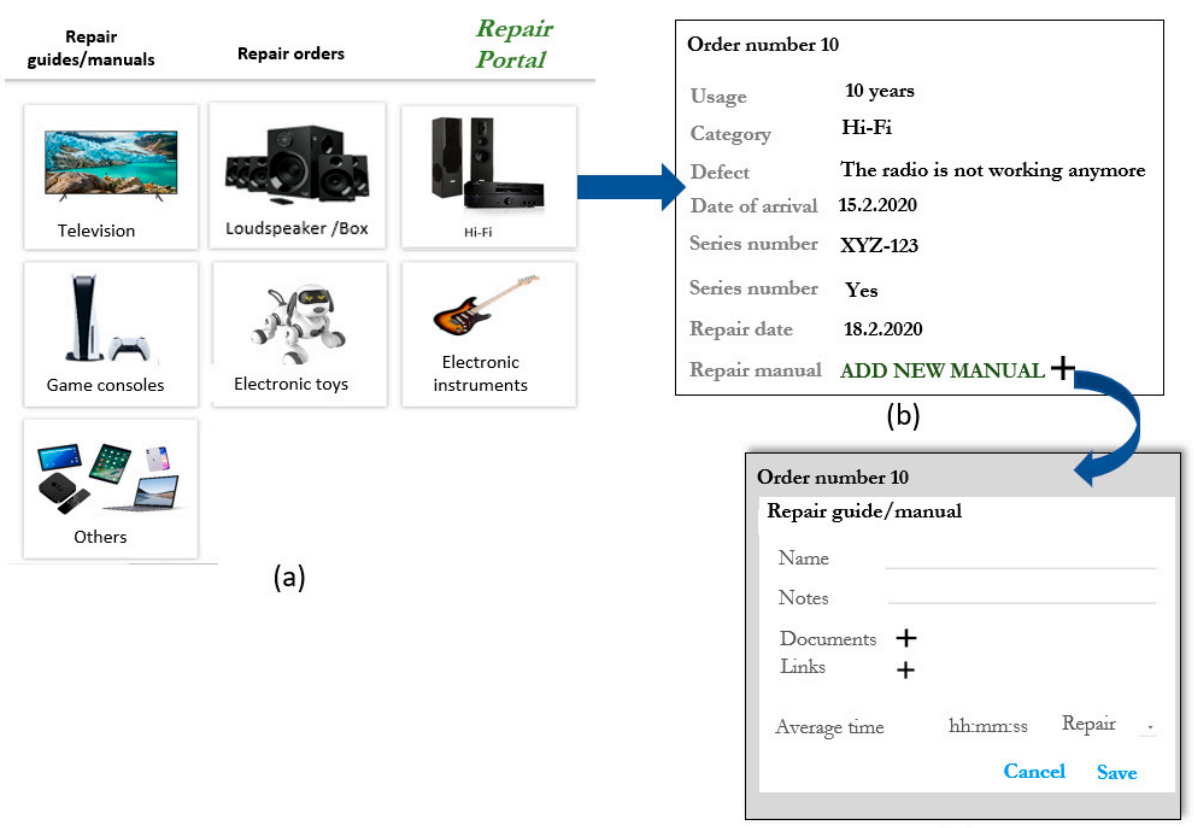

(c)

Figure 9. Screenshots of the repair portal: (a) overview and detail views of the (b) order and (c) adding repair manual, including details.

\section{Conclusions}

In the context of the Circular Economy, repair is a necessary and useful cascade to extend the use phase of EEE. Currently, offering attractive repair services fails due to various challenges, which are explained from a customer, product as well as legal perspective. The identification of relevant stakeholders in the repair sector shows that the main actors are the repairer, as the provider of the services, and, to a large extent, the customer, as the decision-maker about the further life cycle of the EEE. The demand for different repair services depends, in particular, on the attitude of the users and their requirements. A repair study and accompanying surveys were carried out and confirmed many findings of barriers mentioned in literature, especially regarding high costs resulting from personnel and spare parts costs. Furthermore, it could be shown that the most frequent error patterns of EEE were in the mechanics and the motor, for which a repair was often successful. Another common error pattern was the circuit board. Spare parts or information of circuit boards, especially of older EEE, can be difficult to obtain. On this basis, generally applicable recommendations for actions were derived. Furthermore, as a concrete solution, a repair portal has been presented that aims at offering attractive repair services.

Based on the lessons learned in the repair study, a second phase will be conducted in the repair study, with a focus on the optimization of repair time and costs as one of the largest barriers. The optimization will be based on a software solution by establishing the proposed repair portal. We plan to extend the repair portal with a web crawler for spare 
parts procurement in the future. Thus, although process accelerators such as repair manuals or web crawlers for spare parts' search can significantly reduce repair time, personnel costs remain high and hinder an attractive repair offer. In addition, further barriers should be minimized, e.g., by involving not only customers and repairers as the main actors, but all actors in the Circular Economy. For the greatest possible benefit, cross-cascade stakeholder networking should take place, e.g., for selling second-hand spare parts. This can be implemented, for example, in the form of an online marketplace.

Author Contributions: Conceptualization and Methodology, S.R., S.B., J.F.N., S.L., P.S., S.H., M.M. and K.S.; Writing—original draft, Investigation and Visualization, S.R., S.B., J.F.N., S.L., P.S. and S.H.; Writing-review \& editing, M.M., C.H., A.R., K.S., T.S.S., S.R., S.B., J.F.N., S.L., P.S. and S.H.; Resources and Funding Acquisition, C.H., A.R. and T.S.S.; Supervision M.M. and K.S. All authors have read and agreed to the published version of the manuscript.

Funding: This research was funded by the German Federal Ministry of Education and Research (BMBF), grant number 033R240C (project title "EffizientNutzen-data-based business models for the cascade usage and extended product usage of electr(on)ic products").

Institutional Review Board Statement: Not applicable.

Informed Consent Statement: Informed consent was obtained from all subjects involved in the study. Data Availability Statement: Not applicable.

Acknowledgments: All project partners in "EffizientNutzen" should be acknowledged for their great collaboration. Special thanks go to Robert Bosch GmbH, Automotive Aftermarket, Electronic Service for their contribution.

Conflicts of Interest: The authors declare no conflict of interest. The funders had no role in the design of the study; in the collection, analyses or interpretation of data; in the writing of the manuscript or in the decision to publish the results.

\section{References}

1. Forti, V.; Baldé, C.; Kuehr, R.; Bel, G. The Global E-Waste Monitor 2020. Quantities, Flows, and the Circular Economy Potential; International Solid Waste Association: Rotterdam, The Netherlands, 2020; ISBN 978-92-808-9114-0.

2. World Economic Forum. A New Circular Vision for Electronics: Time for a Global Report; World Economic Forum: Colony, Switzerland, 2019.

3. Prakash, S.; Dehoust, G.; Gsell, M.; Schleicher, T.; Stamminger, R. Einfluss der Nutzungsdauer von Produkten auf ihre Umweltwirkung: Schaffung einer Informationsgrundlage und Entwicklung von Strategien gegen "Obsoleszenz". Umweltforsch. Des Bundesminist. Für Umw. Nat. Bau Und Reakt. 2016, 11, 315.

4. Umweltbundesamt Analyse der Datenerhebungen nach ElektroG und UStatG über das Berichtsjahr 2018 zur Vorbereitung der EUBerichtspflichten; EU: Maastricht, The Netherlands, 2020; p. 85.

5. Kirchherr, J.; Reike, D.; Hekkert, M. Conceptualizing the circular economy: An analysis of 114 definitions. Resour. Conserv. Recycl. 2017, 127, 221-232. [CrossRef]

6. Europäisches Parlament Directive 2008/98/EC of the European Parliament and of the Council of 19 November 2008 on Waste and Repealing Certain Directives: Directive 2008/98/EC 2008; European Union: Maastricht, The Netherlands, 2008.

7. Rudolf, S.; Blömeke, S.; Sharma, P.; Lawrenz, S.; Scheller, C.; Mennenga, M.; Schmidt, K.; Herrmann, C.; Rausch, A.; Spengler, T. Efficient Use -An interdisciplinary framework towards the cascade use of electronics. In Proceedings of the Electronics Goes Green 2020+, Berlin, Germany, 1-3 September 2020; Fraunhofer, I.Z.M., Ed.; Fraunhofer: Wessling, Germany, 2020.

8. Boldoczki, S.; Thorenz, A.; Tuma, A. The environmental impacts of preparation for reuse: A case study of WEEE reuse in Germany. J. Clean. Prod. 2020, 252, 119736. [CrossRef]

9. Eisenriegler, S. (Ed.) Kreislaufwirtschaft in der EU; Springer Fachmedien: Wiesbaden, Germany, 2020.

10. Laitala, K.; Klepp, I.G.; Haugrønning, V.; Throne-Holst, H.; Strandbakken, P. Increasing repair of household appliances, mobile phones and clothing: Experiences from consumers and the repair industry. J. Clean. Prod. 2021, 282, 125349. [CrossRef]

11. Parajuly, K.; Kuehr, R.; Awasthi, A.K.; Fitzpatrick, C.; Lepawsky, J.; Smith, E.; Widmer, R.; Zeng, X. Future E-Waste Scenarios; StEP: Bonn, Germany; UNU ViE-SCYCLE: Bonn, Germany; UNEP IETC: Osaka, Japan, 2019.

12. Richter, J.L.; Dalhammar, C. Stakeholders, drivers and barriers for local electronics repair: A case study of southern Sweden. In Proceedings of the PLATE-Product Lifetimes and the Environment: 3rd PLATE Conference, Berlin, Germany, 18-20 September 2019.

13. Nazli, T. Repair motivation and barriers model: Investigating user perspectives related to product repair towards a circular economy. J. Clean. Prod. 2021, 289, 125644. [CrossRef] 
14. Cobbing, M.; Kruszewska, I.; Jardim, E.; Santen, M. How Repairable Is Your Mobile Device? A Product Guide to Best-Selling Smartphones, Tablets and Laptops; Greenpeace: Amsterdam, The Netherlands, 2017.

15. Raihanian Mashhadi, A.; Esmaeilian, B.; Cade, W.; Wiens, K.; Behdad, S. Mining consumer experiences of repairing electronics: Product design insights and business lessons learned. J. Clean. Prod. 2016, 137, 716-727. [CrossRef]

16. Sabbaghi, M.; Behdad, S. Consumer decisions to repair mobile phones and manufacturer pricing policies: The concept of value leakage. Resour. Conserv. Recycl. 2018, 133, 101-111. [CrossRef]

17. Tecchio, P.; Ardente, F.; Mathieux, F. Understanding lifetimes and failure modes of defective washing machines and dishwashers. J. Clean. Prod. 2019, 215, 1112-1122. [CrossRef]

18. Svensson-Hoglund, S.; Richter, J.L.; Maitre-Ekern, E.; Russell, J.D.; Pihlajarinne, T.; Dalhammar, C. Barriers, enablers and market governance: A review of the policy landscape for repair of consumer electronics in the EU and the U.S. J. Clean. Prod. 2021, 288, 125488. [CrossRef]

19. Pérez-Belis, V.; Braulio-Gonzalo, M.; Juan, P.; Bovea, M.D. Consumer attitude towards the repair and the second-hand purchase of small household electrical and electronic equipment. A Spanish case study. J. Clean. Prod. 2017, 158, 261-275. [CrossRef]

20. Lundgren, K. The Global Impact of E-Waste: Addressing the Challenge; ILO Library: Geneva, Switzerland, 2012.

21. Müller, F.; Kohlmayer, R.; Krüger, F.; Kosmol, J.; Krause, S.; Dorer, C.; Röhreich, M. 9 Principles for a Circular Economy; Umweltbundesamt: Dessau-Roßlau, Germany, 2020.

22. Schweitzer, J.-P.; Zuloaga, F.; Anastasio, M.; Arditi, S. Coolproducts Don't Cost the Earth: Full Report 2019; European Environmental Bureau: Brussels, Belgium, 2019.

23. De Jesus, A.; Mendonna, S. Lost in Transition? Drivers and Barriers in the Eco-Innovation Road to the Circular Economy. SSRN Electron. J. 2017, 145, 75-89. [CrossRef]

24. Prakash, S.; Dehoust, G.; Gsell, M.; Schleicher, T.; Stamminger, R. Influence of the Service Life of Products in Terms of Their Environmental Impact: Establishing an Information Base and Developing Strategies against "Obsolescence"; Umweltbundesamt: DessauRoßlau, Germany, 2020.

25. Ryan-Fogarty, Y.; Casey, K.; Coughlan, D.; Lichrou, M.; O'malley, L.; Fitzpatrick, C. An Investigation into WEEE Arising and Not Arising in Ireland (EEE2WEEE); Environmental Protection Agency: Washington, DC, USA, 2017.

26. Abeliotis, K.; Boikou, K.; Chroni, C.; Kalafata, K.; Angelakopoulos, H.; Lasaridi, K. WEEE Preparing for Reuse in Greece: Potential and Initiatives. Waste Biomass Valorization 2021, 12, 2959-2968. [CrossRef]

27. Yeh, B.T. Repair, Modification, or Resale of Software-Enabled Consumer Electronic Devices: Copyright Law Issues; Congressional Research Service: Washington, DC, USA, 2016.

28. Svensson, S.; Richter, J.L.; Maitre-Ekern, E.; Pihlajarinne, T. The Emerging 'Right to Repair' legislation in the EU and the U.S.; Going Green CARE: Vienna, Austria, 2018.

29. Brusselaers, J.; Bracquene, E.; Peeters, J.; Dams, Y. Economic consequences of consumer repair strategies for electrical household devices. J. Enterp. Inf. Manag. 2020, 33, 747-767. [CrossRef]

30. McCollough, J. Factors impacting the demand for repair services of household products: The disappearing repair trades and the throwaway society. Int. J. Consum. Stud. 2009, 33, 619-626. [CrossRef]

31. McCollough, J. The effect of income growth on the mix of purchases between disposable goods and reusable goods. Int. J. Consum. Stud. 2007, 31, 213-219. [CrossRef]

32. Box, J.M.F. Extending Product Lifetime: Prospects and Opportunities. Eur. J. Mark. 1983, 17, 34-49. [CrossRef]

33. McCollough, J. The impact of consumers' time constraint and conspicuous consumption behaviour on the throwaway society. Int. J. Consum. Stud. 2020, 44, 33-43. [CrossRef]

34. Atasu, A.; Sarvary, M.; van Wassenhove, L.N. Remanufacturing as a Marketing Strategy. Manage. Sci. 2008, 54, 1731-1746. [CrossRef]

35. McLaren, A.; McLauchlan, S. Crafting Sustainable Repairs: Practice-Based Approaches to Extending the Life of Clothes; PLATE: Delft, The Netherlands, 2015.

36. Götz, T.; Adisorn, T.; Tholen, L. Der Digitale Produktpass als Politik-Konzept; Wuppertal Institut für Klima, Umwelt, Energie: Wuppertal, Germany, 2021.

37. Wieser, H.; Tröger, N. Exploring the inner loops of the circular economy: Replacement, repair, and reuse of mobile phones in Austria. J. Clean. Prod. 2018, 172, 3042-3055. [CrossRef]

38. Rivera, J.L.; Lallmahomed, A. Environmental implications of planned obsolescence and product lifetime: A literature review. Int. J. Sustain. Eng. 2016, 9, 119-129. [CrossRef]

39. Huang, C.-C.; Liang, W.-Y.; Yi, S.-R. Cloud-based design for disassembly to create environmentally friendly products. J. Intell. Manuf. 2017, 28, 1203-1218. [CrossRef]

40. Babbitt, C.W.; Madaka, H.; Althaf, S.; Kasulaitis, B.; Ryen, E.G. Disassembly-based bill of materials data for consumer electronic products. Sci. Data 2020, 7, 251. [CrossRef] [PubMed]

41. Schweitzer, J.-P.; López Dávila, M.; Luth Richter, J.; Dalhammar, C.; Mikolajczak, C. Removable, Replaceable and Repairable Batteries; European Environmental Bureau: Brussels, Belgium, 2021.

42. Sabbaghi, M.; Cade, W.; Behdad, S.; Bisantz, A.M. The current status of the consumer electronics repair industry in the U.S.: A survey-based study. Resour. Conserv. Recycl. 2017, 116, 137-151. [CrossRef] 
43. Walther, G.; Steinborn, J.; Spengler, T.S.; Luger, T.; Herrmann, C. Implementation of the WEEE-directive - economic effects and improvement potentials for reuse and recycling in Germany. Int. J. Adv. Manuf. Technol. 2010, 47, 461-474. [CrossRef]

44. Guldmann, E.; Huulgaard, R.D. Barriers to circular business model innovation: A multiple-case study. J. Clean. Prod. 2020, 243, 118160. [CrossRef]

45. Bakhiyi, B.; Gravel, S.; Ceballos, D.; Flynn, M.A.; Zayed, J. Has the question of e-waste opened a Pandora's box? An overview of unpredictable issues and challenges. Environ. Int. 2018, 110, 173-192. [CrossRef]

46. Europäisches Parlament. Europäischer Rat Richtlinie 2011/65/EU des Europäischen Parlaments und des Rates vom 8 . Juni 2011 zur Beschränkung der Verwendung Bestimmter Gefährlicher Stoffe in Elektro- und Elektronikgeräten; Amtsblatt der Europäischen Union: Brussels, Belgium, 2011.

47. Europäisches Parlament. Europäischer Rat Richtlinie 2012/19/EU des Europäischen Parlaments und des Rates vom 4. Juli 2012 über Elektro- und Elektronik-Altgeräte; Amtsblatt der Europäischen Union: Brussels, Belgium, 2012.

48. Europäisches Parlament. Europäischer Rat Richtlinie 2009/125/EG des Europäischen Parlaments und des Rates vom 21. Oktober 2009 zur Schaffung eines Rahmens für die Festlegung von Anforderungen an die Umweltgerechte Gestaltung Energieverbrauchsrelevanter Produkte; Amtsblatt der Europäischen Union: Brussels, Belgium, 2009.

49. Europäisches Parlament. Europäischer Rat Verordnung (EU) 2019/2021 der Kommission vom 1. Oktober 2019 zur Festlegung von Ökodesign-Anforderungen an elektronische Displays gemäßder Richtlinie 2009/125/EG des Europäischen Parlaments und des Rates, zur Änderung der Verordnung (EG) Nr. 1275/2008 der 2019; Amtsblatt der Europäischen Union: Brussels, Belgium, 2019.

50. Europäisches Parlament. Europäischer Rat Verordnung (EU) 2019/2022 der Kommission vom 1. Oktober 2019 zur Festlegung von Ökodesign-Anforderungen an Haushaltsgeschirrspüler gemäßder Richtlinie 2009/125/EG des Europäischen Parlaments und des Rates, zur Änderung der Verordnung (EG) Nr. 1275/2008 de 2019; Amtsblatt der Europäischen Union: Brussels, Belgium, 2019.

51. Monier, V.; Tinetti, B.; De Prado Trigo, A.; Ax, C.; Medhurst, J.; Mitsios, A. Study on Socioeconomic Impacts of Increased Reparability of Increased Reparability; European Commission, Directorate-General for Environment: Brussels, Belgium, 2016.

52. Jaeger-Erben, M.; Frick, V.; Hipp, T. Why do users (not) repair their devices? A study of the predictors of repair practices. J. Clean. Prod. 2021, 286, 125382. [CrossRef]

53. Motorola Phone Repair at iFixit. Available online: https:/ / www.ifixit.com/Motorola (accessed on 28 February 2022).

54. Milios, L. Towards a Circular Economy Taxation Framework: Expectations and Challenges of Implementation. Circ. Econ. Sustain. 2021, 1, 477-498. [CrossRef]

55. Verbraucherzentrale Thüringen e.V. Reparaturbonus Thüringen. Available online: https://www.reparaturbonus-thueringen.de/ (accessed on 31 January 2022).

56. Mitteldeutscher Rundfunk. Ein Monat Reparaturbonus in Thüringen: Schon 1.000 Anträge bewilligt I MDR.DE. Available online: https://www.mdr.de/nachrichten/thueringen/reparaturbonus-umwelt-tausend-geraete-100.html (accessed on 31 January 2022).

57. Dalhammar, C.; Hartman, C.; Larsson, J.; Jarelin, J.; Milios, L.; Mont, O. Moving Away from the Throwaway Society. Five Policy Instruments for Extending the Life of Consumer Durables; Chalmers University of Technology: Gothenburg, Sweden, 2022.

58. Heinz, R.; Meyer, K. Der Französische Reparaturindex: Ein Modell für Deutschland und die EU; Germanwatch: Bonn, Germany, 2020.

59. Grieves, M. (Ed.) Digital Twin: Manufacturing Excellence through Virtual Factory Replication. Whitepaper; Michael W. Grieves, LLC: Cocoa Beach, FL, USA, 2014.

60. MediaMarkt. PlusSchutz: So Schützen Sie Ihr Neues Gerät. Available online: https://www.mediamarkt.de/de/service/garantieversicherung/plusschutz (accessed on 31 January 2022).

61. Wertgarantie SE. Elektrogeräte \& Fahrräder Schützen I WERTGARANTIE. Available online: https://www.wertgarantie.de/ schuetzen\#/ (accessed on 31 January 2022).

62. Wertgarantie SE. Reparieren Statt Wegwerfen: Eine Studie im Auftrag der WERTGARANTIE SE zur Entstehung von Elektroschrott; WERTGARANTIE Beteiligungen GmbH: Hanover, Germany, 2021.

63. Hischier, R.; Böni, H.W. Combining environmental and economic factors to evaluate the reuse of electrical and electronic equipment-A Swiss case study. Resour. Conserv. Recycl. 2021, 166, 105307. [CrossRef] 